\title{
A PSICANÁLISE LACANIANA E O GRUPO: DESDOBRAMENTOS DE UMA ÉTICA DE TRABALHO
}

Evelyn Cássia De Souza Silva, Joana Sanches Justo

Universidade do Oeste Paulista - UNOESTE, Curso de Psicologia, Presidente Prudente, SP, E-mail: evellyn ghee2008@hotmail.com

\section{RESUMO}

Desde o surgimento da psicanálise, o profissional de psicologia é direcionado para o atendimento clínico individual. Mas com o passar dos anos e com as grandes demandas, faz-se necessário pensar a respeito do atendimento grupal e, principalmente, é preciso pensar em uma conduta ética do psicólogo no trabalho com grupos. Dessa forma, a presente pesquisa buscou investigar as possibilidades de um trabalho com grupo embasado na Psicanálise Lacaniana, através de uma pesquisa bibliográfica, para assim recuperar os conhecimentos científicos produzidos até o momento. Concluímos que é possível conduzir um trabalho em grupo, mas não da mesma forma que em uma análise.

Palavras-chave: Psicanálise, Lacan, ética, Psicoterapia Grupal.

\section{LACANIAN PSYCHOANALYSIS AND THE GROUP: DEPLOYMENTS OF A WORK ETHICS}

\begin{abstract}
Since the beginning of psychoanalysis, the psychologist is directed to individual clinical care. But over the years and with greater demands, it is necessary to think about the group service and, mainly, it is necessary to think about an ethical conduct of the psychologist in the work with groups. Thus, the present research sought to investigate the possibilities of a work with groups based on the Lacanian psychoanalysis, through a bibliographical research, in order to recover the scientific knowledge produced up to the present and with this we conclude that it is possible to conduct a psichoanalitical group work, but not in the same way as in an analysis.
\end{abstract}

Keywords: Psychoanalysis, Lacan, Ethics, Group Psychotherapy 


\section{INTRODUÇÃO}

Desde a prática de Freud com a psicanálise, a sua atuação clínica sempre foi orientada para o atendimento individual. No entanto, com a ampliação dos campos de atuação da psicologia, o psicólogo está tendo que se direcionar cada vez mais para instituições e serviços de saúde da rede pública, e por causa da demanda que é muito grande fica inviabilizada a psicoterapia individual e estes acabam formando grupos, como uma forma de mostrar que estão prestando serviço. Muitas vezes à essa forma de atuação falta embasamento teórico para a prática haja vista a falta de produção cientifica nesta temática.

Assim, o presente artigo visa subsidiar discussões a respeito do tema em questão, tomando o referencial psicanalítico lacaniano para assim trazer à tona questionamentos e aberturas para se pensar o trabalho do psicólogo com grupos em termos éticos e, conseguintemente, para que a psicoterapia grupal não seja um mero instrumento para conseguir dar conta de demandas numerosas.

É importante nos atentarmos ao fato de termos encontrado poucas publicações sobre a temática, sendo que uma parte significativa está vinculada a outras áreas de atuação e/ou a outras abordagens teóricas. Diante deste contexto, o presente estudo se baseou nos escritos do CostaRosa, que estuda a psicoterapia grupal usando a abordagem lacaniana no contexto da saúde coletiva; de Freud, que por meio da associação livre desenvolveu a psicanálise, e de Lacan, que se opões aos pós-freudianos e promoveu um retorno a Freud.

Sabe-se que a Psicanálise se dá "per via de levare" onde se busca extrair o que se tem sem fazer sugestões ao paciente (FREUD, 1905 [1904], pag. 270). No entanto, inicialmente a psicanálise é uma psicoterapia, visto que esta pertencia a medicina e tinha como objetivo a cura (MEZAN, 1996). Mas com os avanços da psicanálise, muda-se o foco, que deixa de ser a cura para alcançar os conteúdos inconscientes, tornando-os conscientes (FREUD, 1904). Foi a partir das psicoterapias que Freud propôs a psicanálise, ou seja, por mais que ambas tenham solo comum, ainda assim não são a mesma coisa (FREUD, 1905 [1904]).

Dessa forma, fica o questionamento sobre a possibilidade de atendimentos em grupo usando os pressupostos teóricos da psicanálise lacaniana, mantendo sua ética, eficiência e eficácia. Com o intuito de expor essa nova possibilidade de trabalho com grupos fez-se necessário discorrer sobre os conceitos de transferência e ética, que são elementos fundamentais para que ocorra uma psicanálise. Inicialmente foi discutida a transferência, o deslocamento que se faz da pessoa do passado para a pessoa do analista no tempo presente, visto que é de extrema importância, pois não existe psicanálise sem neurose de transferência. Depois passamos a discutir a postura do psicólogo, de como deve ser o modo de agir em seu ofício, sustentando assim sua posição e a ética com a psicanálise. E por último, busca-se defender a ética lacaniana que pode ser exercida também em grupos, no posicionamento do psicanalista.

\section{À TRANSFERÊNCIA NO TRABALHO PSICANALÍTICO}

$\mathrm{Na}$ relação de transferência as experiências passadas do indivíduo se apresentam transpostas para o terapeuta e para os demais membros do grupo, isto é, ocorre uma repetição de conteúdos que não foram anteriormente elaborados ou significados que é uma resistência que precisa ser desencoberta para que os materiais inconscientes cheguem à consciência, o que proporcionará o preenchimento das "lacunas da recordação" (FREUD, 1911, pg. 195).Mas a transferência não é uma repetição inconsciente, mas uma atualização da realidade inconsciente que se dá por meio da atuação, onde o paciente vive seus problemas como algo do presente, transpostos para o setting analítico (FREUD, 1911).

Na perspectiva lacaniana (LACAN, 1998), a transferência está intrinsecamente ligada ao "sujeito suposto saber", pois o sujeito tem a ilusão de que o analista tem acesso ao saber do seu inconsciente, ou seja, sabe todas as respostas pro seu problema. No entanto o terapeuta não deve 
ocupar este lugar, pois a única pessoa que tem o saber sobre o sofrimento do paciente é ele mesmo (PISETTA, 2011).

A respeito de como se da à transferência em um trabalho analítico podemos dizer que o analista convida o paciente a ter um encontro consigo mesmo e busca fazer com que o paciente conduza livremente sua fala durante a sessão, sendo que suas interferências servem para manter a associação livre, que é a regra fundamental da psicanálise (FREUD, 1913). É através do método da associação livre, que o paciente vai tornando consciente o que antes era inconsciente, ou seja, com a superação das resistências é possível trazer à consciência o material psíquico inconsciente e assim trabalhá-lo (FREUD, 1912).

No trabalho em grupo a transferência se dá com um grupo de pessoas e não somente com um individuo, portanto, a transferência não é focada somente em paciente-terapeuta, mas sim no paciente e todos os demais envolvidos. Segundo Rosa (2011) no grupo é de fundamental importância a participação de todos, ou seja, eles precisam se expor, pois para Pratta e Costa-Rosa (2011) "o grupo psicoterapêutico é um dispositivo de produção coletiva" (pg. 681). Podemos então apontar a diferença entre produção e análise, portanto o que o autor entende como escopo do trabalho em grupo é uma produção coletiva, mas uma análise, em que cada caso é tomado no seu particular, é individual. No percurso de uma análise a direção aponta para o inconsciente do sujeito, não para uma coletividade do inconsciente, ainda que Freud (1921) tenha afirmado que toda psicologia individual, por se tratar da relação do sujeito com o outro, é social.

Na produção em grupo o sujeito consegue reconhecer que não é o único a sofrer, pois se conecta ao grupo a partir de uma identificação imaginária por meio do sintoma (PRATTA; COSTAROSA, 2011), ou seja, o paciente encontra nos demais membros suas próprias problemáticas. É em grupo que o paciente consegue se ouvir e simbolizar suas problemáticas, assim vai se conhecendo, melhorando seu bem-estar e modificando seus comportamentos (ROSA, 2011).

\section{A POSTURA DO PSICÓLOGO DE ORIENTAÇÃO PSICANALÍTICA}

Não existe um manual de passo a passo de como se fazer psicanálise e muito menos de como usá-la em grupo. Mas o psicólogo que vai trabalhar com grupos, deve colocar em prática as recomendações deixadas por Freud. Pois assim como o analista, este tem que estar consciente que o saber não está com ele e sim com o outro. Segundo Pratta e Costa-Rosa (2011), o terapeuta não deve dar respostas, mesmo quando solicitado, pois o saber dever ser produzido pelos próprios sujeitos. Em momento algum o psicoterapeuta deve fazer sugestões, dar conselhos sobre o problema do paciente, pois se isso acontece ele acaba ajudando o paciente a mascarar o que o inconsciente the traz (FREUD, 1912b). Diante dos pressupostos Lacaniano, o analista deve abandonar seu eu, deixar de lado seus valores, pessoalidades e possíveis julgamentos. Ou seja, ele deve se silenciar para poder escutar o que é dito pelo paciente (NASIO, 1999).

$\mathrm{O}$ analista deve manter a sua atenção flutuante, ou seja, deixar a própria atividade mental funcionar livremente, para que assim possa conseguir interpretar, perceber e causar o inconsciente, pois assim o próprio sujeito vai se exercitando para perceber-se autor de sua história e superar uma posição/lugar em que é objeto do desejo ou de gozo de outros (FREUD, 1912b).

Nesse sentido, para Lacan (1998a), estudando a direção do tratamento a partir das considerações de Freud, o "psicanalista dirige o tratamento, mas não o paciente" (pg. 586) (PRATTA; COSTA-ROSA, 2011, pg. 681). Por isso, é necessário manter a mesma "atenção uniformemente suspensa" diante de tudo o que se escuta (FREUD, 1912).

A psicanálise não opera com a questão do ser do analista, pois este coloca seu ser fora de análise, pois é com "o desejo do analista o instrumento no qual o analisante que se tornou analista vai operar, por sua vez, na condução do tratamento analítico de seus analisantes" (QUINET, 2008, pg. 110). Ou seja, o analista opera com seu desejo na condução de uma análise, mas é antiético colocar em análise seus desejos inconscientes, visto que o espaço é para o analisante e não para o 
analista (QUINET, 2008). Se o ser do analista entra em jogo, não se sabe quem fala e não se sabe quem está dirigindo o tratamento (LACAN, 1998a, pag. 589).

A finalidade da análise é fazer com que o paciente por si mesmo, produza sua "verdade", um saber sobre a verdade (LEITE, 2010). A análise deve possibilitar uma nova relação do sujeito com o real (LACAN, 1992), portanto, em análise o analista não entra como sujeito, mas como objeto, como um lugar vazio (LACAN, 2003; QUINET, 2008). Em grupo, segundo Pratta e CostaRosa (2011), ocorre a produção de sentido novo, onde as interpretações também podem surgir dos próprios integrantes, pois o analista não se limita a isso, em fazer circular a palavra, mas sim, em fazê-la surgir (pg. 681).

\section{A ÉTICA DA PSICANÁLISE EM LACAN}

A análise se dá pelo desejo inconsciente e pelo compromisso que se estabelece entre sujeito e seu desejo e a ética por sua vez, está intimamente ligada a esses fatores.

Quando uma pessoa busca por tratamento é porque alguma angústia indefinida apareceu e na esperança de que tudo se resolva, o sujeito busca na análise uma solução, a cura. E aos olhos do sujeito, este profissional é o dono do saber, o "Outro", um ser capaz de lhe trazer satisfação (LEITE, 2000). O paciente demanda de terceiros, algo que ele "não tem". Busca que estes encontrem a satisfação pra ele, pois não quer correr o risco de não se restabelecer de um sofrimento. $O$ sujeito demanda um saber que resolva seus problemas (COSTA-ROSA; PASTORI, 2011).

O sujeito é afetado pelo desejo e determinado pelo Outro e vive por toda vida correndo atrás de algo que o complete e supra a falta (FREUD, 1924). Da mesma forma é quando este se encontra em análise, visto que tem a fantasia de que o analista pode suprir isso.

Em um tratamento de abordagem psicanalítica lacaniana, quem deve falar é o paciente, para que assim ele se aproxime e possa se apropriar de seu saber inconsciente (LEITE, 2010). Para Lacan, o papel do analista é fazê-lo falar e, apoiado em sua tática e estratégica no manejo transferencial, dirigir a cura (LACAN, 1998). O analista por sua vez deve renunciar seu desejo - pois quem está em análise não é ele e adverte Lacan nesse mesmo texto que é melhor o analista se concentrar mais em sua falta-a-ser do que em seu ser no exercício de seu ofício. Essa é a ética da psicanálise, que ao apontar para o um-a-um, permite que o sujeito resgate em seu discurso a série de significantes ao qual está alienado seu desejo ao Outro e, assim, reconstruir sua história e reposicionar-se subjetivamente. Para tanto, é importante que o analista esteja atento ao sujeito do inconsciente, sujeito de desejo - e deixe um lugar vazio, pague com seu ser e com suas interpretações, para que um sujeito possa advir.

\section{ANALISE E DISCUSSÃO DOS RESULTADOS}

Concluída essa exposição que cumpre a função de nos introduzir na complexa teoria psicanalítica elaborada por Freud e continuada por Lacan, é importante sistematizar as principais implicações da psicanálise lacaniana para o trabalho com grupos. Sem a possibilidade de esgotarmos essa análise, destacaremos aqui cinco proposições fundamentais.

A primeira decorre da afirmação de que não é possível conduzir um trabalho em grupo da mesma forma que em uma análise. Em grupo ocorre uma terapia através do grupo. Mas o trabalho em grupo é tão eficaz quanto o trabalho individual, de acordo com Costa-Rosa. O paciente avança na medida em que rompe as resistências e elabora os conteúdos (FREUD, 1915). Do mesmo jeito que o sofrimento que o sujeito traz é individual, a apropriação do saber também será individual, mesmo tendo sido produzido em um funcionamento coletivo. O psicólogo ao trabalhar em grupo, portanto, deve oferecer a escuta além do dito, que é um suporte para o paciente que se encontra em um processo de adoecimento, e em um segundo momento deve o 
inserir em um trabalho em grupo possibilitando a formação do grupo, para que ocorra a produção de sentidos novos.

A segunda proposição refere-se à compreensão de que quanto mais perto dos conteúdos inconscientes, maiores serão as distorções, as resistências (FREUD, 1900). O processo analítico não é um processo linear, que vai sempre causando melhoras ao paciente, mas envolve progresso, modificações e por vezes decaída. Portanto, é fundamental que o psicólogo esteja atento a esses movimentos. É importante que o psicólogo consiga compreender esse período critico, para conseguir dar suporte ao paciente para que este continue no grupo, evitando assim as evasões.

Como terceira proposição, gostaríamos de destacar a importância do comprometimento do psicólogo com o grupo. Isso significa que não basta apenas o psicólogo usar do grupo como uma forma de acabar com as longas filas de espera. O profissional precisa estar presente, pois este será uma referência para que o paciente busque um tratamento individual e acredite que ele é eficaz. Esse comprometimento do psicólogo com o trabalho em grupo é de extrema importância, principalmente para que essa modalidade de trabalho venha a ser conhecida e reconhecida como uma técnica eficiente e eficaz de trabalho, fazendo com que possibilite maiores demandas espontâneas.

Como quarta proposição, destacamos a importância de compreender o referencial teórico e compreender qual é a proposta de trabalho. $O$ inconsciente não é algo estático, algo acabado, mas em movimento. É preciso atentar, portanto, que ao se trabalhar um conflito, novos podem surgir, o que deixa claro que é impossível determinar tempo para o término do grupo. A alta será dada pelo próprio paciente, este é que vai decidir continuar ou não no grupo.

Por fim, como quinta e última proposição, não acreditamos que tenha perda no trabalho em grupo, talvez a maior perda nesse trabalho seja querer defender a aplicabilidade da psicanálise no trabalho grupal, sendo que é melhor trazer questões sobre a ética do desejo, a postura analítica que facilmente pode recair em uma impostura. Esse tipo de discussão, esse sim, pode ajudar os psicólogos que estão aí na prática institucional se vendo obrigado a dar conta de atendimentos grupais. Mais do que justificar que serve pro grupo, discutir para que pode servir ao analista no seu ofício.

Portanto, profissionais que pretendem ou dizem seguir tal referencial teórico e pretendem trabalhar com grupos, devem desenvolver a escuta analítica para onde quer que leve seu trabalho.

\section{CONCLUSÃO}

O trabalho em grupo deve ser pautado em uma postura ética, pois a escuta e a ética da psicanálise é que deve acompanhar o psicanalista para onde quer que vá, para além da técnica, do setting. A escuta e a ética é do analista, e é um posicionamento de não ter que tamponar a falta, é um posicionamento onde se aposta no surgimento de um sujeito, mas que o analista paga com seu ser, paga com seu desejo e deixa o lugar vazio para que o paciente possa ocupa-lo com suas fantasias, em transferência. Dessa forma, não é possível conduzir um trabalho em grupo da mesma forma que em uma análise.

Portanto, mesmo sendo observados resultados significativos nos trabalhos de Costa-Rosa que é o único autor a produzir conhecimento a cerca do trabalho com grupo na abordagem psicanalítica lacaniana, ainda é necessário mais estudos para pode ajudar os psicólogos que estão aí na prática institucional se vendo obrigado a dar conta de atendimentos grupais. Ou seja, mais do que justificar se a psicanálise serve ou não pro grupo, discutir para que pode servir ao analista no seu ofício, visto que este tem sua escuta analítica para onde quer que o leve seu trabalho. 


\section{REFERÊNCIAS}

COSTA-ROSA, A., PASTORI, F..O grupo psicoterapêutico além do Imaginário: a psicanálise de Lacan, laços sociais e revoluções de discurso. Revista de Psicologia da UNESP, 2011, Vol. 10, n 1, pg. 0123.

FREUD, S. A dissolução do complexo de Édipo, 1924.

FREUD, S. A interpretação dos sonhos, 1900. In: Freud, S. Edição Standard Brasileira das Obras Psicológicas Completas de Sigmund Freud, vol IV, Imagos: Rio de Janeiro, 1970.

FREUD, S. A Dinâmica da transferência, 1912. In: FREUD, S. O caso de Schreber e artigos sobre técnicas. Rio de Janeiro: Imago, 1996.

FREUD, S. O método psicanalítico de Freud, 1904. In: Obras completas - edição Standard Brasileira, v. VII. Rio de Janeiro: Imago.

FREUD, S. O recalque, 1915. In Freud S., Edição Standard Brasileira das Obras Psicológicas Completas de Sigmund Freud, Vol. XIV, Rio de Janeiro: Imago, 1996.

FREUD, S. Recomendações aos médicos que exercem a psicanálise, 1912b. In: Obras completas edição Standard Brasileira , v. XII. Rio de Janeiro: Imago.

FREUD, S. Recordar, Repetir e Elaborar (1911). In: Freud S., Edição Standard Brasileira das Obras Psicológicas Completas de Sigmund Freud, vol XII, Rio de Janeiro, Imago, 1969.

FREUD, S. Sobre o inicio do tratamento, 1913. In: Obras completas - edição Standard Brasileira , v. XII. Rio de Janeiro: Imago.

FREUD, S., Psicologia de Grupo e Análise do ego (1921), ESB, vol. XVIII, pg. 133.

FREUD, S. (1905 [1904]). Sobre a psicoterapia. In: Freud, S., Edição Standard Brasileira das Obras Psicológicas Completas de Sigmund Freud, vol. VII, Rio de Janeiro, Imago, 1969.

LACAN, J. A direção do tratamento e os princípios de seu poder. IN: Escritos. Editora Jorge Zahar: Rio de Janeiro, 1998a.LACAN, J. Intervenção sobre a transferência. Editora Jorge Zahar: Rio de Janeiro, 1998.

MEZAN, R. Psicanálise e psicoterapia. Estudos avançados, 1996, Vol. 10, n²7, pg. 95-108, https://doi.org/10.1590/S0103-40141996000200005.

QUINET, A. A descoberta do inconsciente: do desejo ao sintoma. Editora Jorge Zahar, $3^{\circ}$ edição, 2008. 